

\title{
Role of biochemical and mechanical disintegration on $\beta$-carotene release from steamed and fried sweet potatoes during in vitro gastric digestion
}

Geeshani Somaratne, Aiqian Ye, Francoise Nau, Maria J Ferrua, Didier Dupont, R. Paul Singh, Jaspreet Singh

\section{To cite this version:}

Geeshani Somaratne, Aiqian Ye, Francoise Nau, Maria J Ferrua, Didier Dupont, et al.. Role of biochemical and mechanical disintegration on $\beta$-carotene release from steamed and fried sweet potatoes during in vitro gastric digestion. Food Research International, 2020, 136, pp.109481. 10.1016/j.foodres.2020.109481 . hal-02911717

\section{HAL Id: hal-02911717 \\ https: / hal.inrae.fr/hal-02911717}

Submitted on 4 Aug 2020

HAL is a multi-disciplinary open access archive for the deposit and dissemination of scientific research documents, whether they are published or not. The documents may come from teaching and research institutions in France or abroad, or from public or private research centers.
L'archive ouverte pluridisciplinaire HAL, est destinée au dépôt et à la diffusion de documents scientifiques de niveau recherche, publiés ou non, émanant des établissements d'enseignement et de recherche français ou étrangers, des laboratoires publics ou privés.

\section{(ㅇ)(1) $\$$}

Distributed under a Creative Commons Attribution - NonCommercial - NoDerivatives| 4.0 


\title{
Role of biochemical and mechanical disintegration on $\beta$-carotene release from steamed and fried sweet potatoes during in vitro gastric digestion
}

\author{
Geeshani Somaratne ${ }^{\mathrm{a}, \mathrm{b}}$, Aiqian Ye ${ }^{\mathrm{a}}$, Francoise Nau ${ }^{\mathrm{d}}$, Maria J. Ferrua ${ }^{\mathrm{c}, \mathrm{e}}$, Didier Dupont ${ }^{\mathrm{d}}$, \\ R. Paul Singh ${ }^{\mathrm{c}, \mathrm{f}}$, Jaspreet Singh ${ }^{\mathrm{a}, *}$ \\ ${ }^{a}$ Riddet Institute and Massey Institute of Food Science and Technology, Massey University, Palmerston North, New Zealand \\ ${ }^{\mathrm{b}}$ Department of Food Science and Technology, Faculty of Agriculture, University of Peradeniya, 20450, Sri Lanka \\ ${ }^{\mathrm{c}}$ Riddet Institute, Massey University, Palmerston North, New Zealand \\ ${ }^{\mathrm{d}}$ STLO, INRAE, Institut Agro, 35042 Rennes, France \\ ${ }^{\mathrm{e}}$ Fonterra Research and Development Centre, Palmerston North, New Zealand \\ ${ }^{\mathrm{f}}$ Department of Biological and Agricultural Engineering, University of California, Davis, CA, USA
}

\section{A R T I C L E I N F O}

\section{Keywords:}

Stomach

$\beta$-carotene

Cell wall breakdown

Softening

Mechanical forces

Human gastric simulator

\begin{abstract}
A B S T R A C T
The role of biochemical and mechanical disintegration on $\beta$-carotene release from steamed sweet potatoes (SSP) and fried sweet potatoes (FSP) during in vitro gastric digestion was investigated. Results revealed that, in the absence of mechanical forces generated by the stomach, biochemical digestion did not have a great effect on the breakdown of cell walls within the sweet potato food matrix and the release of ß-carotene was similar in both SSP and FSP. Cell wall in the plant-food may act as a physical 'barrier' towards the action of gastric juice and to the release of nutrients into the gastric digesta. However, FSP underwent quicker softening and collapse during in vitro gastric digestion compared to the compact and denser structure of SSP. This may explain the faster cell wall breakdown and subsequent $\beta$-carotene release from FSP cellular matrix than SSP when mechanical forces are applied as in the human gastric simulator (HGS).
\end{abstract}

\section{Introduction}

$\beta$-carotene is the predominant natural pigment principally responsible for the characteristic deep-orange colour of sweet potatoes (Bengtsson, Brackmann, Enejder, Alminger, \& Svanberg, 2010; Tumuhimbise, Namutebi, \& Muyonga, 2009). It has attracted considerable attention as epidemiological evidence continues to suggest that it may provide protection against cancers and other degenerative diseases (Low, D'Arcy, \& Gidley, 2015). This could be due to its biological and physicochemical properties, especially related to its effects as a natural antioxidant and its provitamin A activity (Low et al., 2015; Schweiggert et al., 2014).

Orange-fleshed sweet potatoes and related products are one of the major sources of $\beta$-carotene compounds in the human diet and they can be an efficient way to deal with vitamin A deficiency (Islam, Nusrat, Begum, \& Ahsan, 2016). B-carotene is physically encapsulated within the parenchyma cells of sweet potato tubers (Mennah-Govela \& Bornhorst, 2016a, 2016b). Thus, bioaccessibility of $\beta$-carotene requires the breaking down of cell walls for the release from the food matrix during food processing and/or digestion and subsequent absorption in the small intestine (Mennah-Govela \& Bornhorst, 2016b; Tumuhimbise et al., 2009).

The major physicochemical transformation of food matrices occurs in the stomach after oral processing (Kong \& Singh, 2008; Singh, Ye, \& Ferrua, 2015). Gastric digestion combines several physicochemical processes (diffusion of gastric fluid, heat transfer, fragmentation, dissolution, enzymatic reactions, etc.) that lead to the formation of a chyme before its entry into the small intestine (Kong \& Singh, 2008, 2009a; Somaratne et al., 2020a). Diffusion of gastric fluid along with acid hydrolysis and enzymatic action help to soften food texture, thus improving the disintegration and nutrient release rate (Drechsler \& Bornhorst, 2018; Kong \& Singh, 2009b). Although the effect of biochemical and mechanical disintegration kinetics in different model food systems (i.e. egg white gels, whey protein gels, dairy gels etc.) on nutrient release during gastric digestion has extensively studied (Guo et al., 2015; Guo, Ye, Lad, Dalgleish, \& Singh, 2014; Le Feunteun et al., 2014; Somaratne et al., 2019, 2020b, 2020c), the mechanism by which the diffusion of the gastric juice affects the mechanical disintegration of

\footnotetext{
Abbreviations: SSP, Steamed Sweet Potatoes; FSP, Fried Sweet Potatoes; HGS, Human Gastric Simulator; LM, Light Microscopy

* Corresponding author.

E-mail address: J.X.Singh@massey.ac.nz (J. Singh).
} 
natural food matrices (i.e. fruits, vegetables etc.) is still far from being fully understood. Previous studies have attempted to classify solid foods into six different classes according to the softening kinetics during gastric digestion with the use of texture analysis methods (Bornhorst, Ferrua, \& Singh, 2015; Drechsler \& Bornhorst, 2018). This classification system is known as food breakdown classification system, which can classify foods based on their material properties and behaviour during in vitro gastric digestion to predict their rate limiting mechanism (i.e. cellular disruption/breakdown, gastric emptying, macro-structural breakdown \& acid absorption) in gastric digestion (Bornhorst et al., 2015). It is useful to apply this classification methodology to a wide variety of food matrices in order to help predicting food behaviour in vivo.

Previous studies provide evidence that the cooking methods of sweet potatoes such as boiling, steaming, frying, and microwave steaming would induce structural changes in sweet potatoes (MennahGovela \& Bornhorst, 2016a, 2016b). These structural modifications play a predominant role in physicochemical changes such as food matrix softening, matrix swelling, cell-cell separations, cell wall breakdown and solid release as a result of in vitro gastric digestion (Mennah-Govela \& Bornhorst, 2016a, 2016b). However, biochemical and mechanical disintegration effects of gastric environment on $\beta$-carotene release from sweet potatoes have received less attention. To bridge the aforementioned knowledge gap, the aim of this study is to investigate the influence of biochemical and mechanical disintegration on the $\beta$-carotene release and softening of steamed and fried sweet potatoes during in vitro gastric digestion.

\section{Materials and methods}

\subsection{Materials}

Orange-fleshed sweet potatoes and canola oil were purchased from a local supermarket in Palmerston North, New Zealand. To reduce the influence of possible variations among the initial samples, the same batch of sweet potatoes was used for the entire analysis. Pepsin (from porcine gastric mucosa, $\geq 250 \mathrm{U} / \mathrm{mg}$ solid), a gastric lipase analogue (from Aspergillus niger $\geq 120,000 \mathrm{U} / \mathrm{mg}$ solid) and $\alpha$-amylase (from Aspergillus oryzae, $\geq 30 \mathrm{U} / \mathrm{mg}$ ) were purchased from Sigma Aldrich, USA. Standard of $\beta$-carotene Type I (95\% purity, UV) was obtained from Sigma Aldrich. All other chemicals were of analytical grade. The simulated salivary fluid (SSF) and simulated gastric fluid (SGF) were prepared using the electrolyte stock solutions according to the harmonised INFOGEST protocol, described in Minekus et al. (2014).

\subsection{Sweet potato sample preparation and cooking}

Orange-fleshed sweet potatoes were peeled with a hand-peeler and cut into strips using a DiTo-Sama ${ }^{\circledR}$ vegetable slicer and dicer machine, followed by cutting the strips into cubes (approximately $5 \mathrm{~mm}$ in length) using a sharp knife. Any strips containing curve surfaces were discarded and cubes were only selected from the interior $(1 \mathrm{~cm}$ distance from the edge) of the sweet potato tuber.

Steamed sweet potatoes (SSP) were prepared according to the method described by Drechsler and Ferrua (2016). Prior to steaming, water was placed at the bottom of the steam cooker and heated up to boiling over $15 \mathrm{~min}$. The temperature of the generated steam reached up to $100 \pm 3{ }^{\circ} \mathrm{C}$. Then, $50 \mathrm{~g}$ of sweet potato cubes were steamed over $1500 \mathrm{~mL}$ of boiling water using a steamer pot ( $25 \mathrm{~cm}$ diameter) with a $1.5 \mathrm{~mm}$ stainless steel sieve mesh for $5 \mathrm{~min}$ and then removed.

The frying method adopted in this study is a method that is typically used in the production of deep-fried potato chips (Farinu \& Baik, 2007). Initially, the canola oil was filled in a Breville Deep Fryer and pre-heated to $180 \pm 2{ }^{\circ} \mathrm{C}$ before frying. Then, $50 \mathrm{~g}$ of sweet potato cubes were placed in a wire mesh basket, which was immersed in the oil for $1.5 \mathrm{~min}$, after the set temperature was reached. A thermocouple was kept inside the frying container during cooking to measure the temperature profile over time to ensure similar cooking conditions for each batch. After frying, the batch of samples was taken out of the oil and allowed to drain for $3 \mathrm{~min}$ before blotting off the surface oil using an absorbent paper.

\subsection{Static in vitro digestion}

SSP and fried sweet potatoes (FSP) samples were digested according to the harmonized INFOGEST protocol (Minekus et al., 2014). Briefly, either steamed or fried orange-fleshed sweet potatoes cubes (5 g) sample was mixed with $4 \mathrm{~mL}$ of pre-heated $\left(37^{\circ} \mathrm{C}\right) \mathrm{SSF}$ electrolyte stock solution. Then, $0.5 \mathrm{~mL}$ salivary $\alpha$-amylase solution of $1500 \mathrm{U} / \mathrm{mL}, 25 \mu \mathrm{L}$ of $0.3 \mathrm{M} \mathrm{CaCl}_{2}\left(\mathrm{H}_{2} \mathrm{O}\right)_{2}$ and $975 \mu \mathrm{L}$ of water were added and thoroughly mixed. The sample was incubated for $2 \mathrm{~min}$ at $37{ }^{\circ} \mathrm{C}$ at $50 \mathrm{rpm}$ in a shaking water bath (BS-11, Lab Companion).

After the oral phase, the sample was mixed with $7.5 \mathrm{~mL}$ of previously warmed $\left(37^{\circ} \mathrm{C}\right.$ ) SGF electrolyte stock solution and $5 \mu \mathrm{L}$ of $0.3 \mathrm{M}$ $\mathrm{CaCl}_{2}\left(\mathrm{H}_{2} \mathrm{O}\right)_{2}$. The pH was adjusted to 3.0 with $1 \mathrm{M} \mathrm{HCl}$. Then, $1.6 \mathrm{~mL}$ porcine pepsin stock solution $(2000 \mathrm{U} / \mathrm{mL}$ in the final mixture) and $1.0 \mathrm{~mL}$ lipase $(120 \mathrm{U} / \mathrm{mL}$ in the final mixture) were added and the volume was adjusted to $20 \mathrm{~mL}$ with water. The sample was incubated at $37{ }^{\circ} \mathrm{C}$ at $50 \mathrm{rpm}$ in a shaking water bath (BS-11, Lab Companion).

The individual sample was used for each replicate of each digestion time. Thus, 24 samples from one cooking treatment (either steamed or fried) were prepared according to the above procedure and placed into the shaking water bath at $37{ }^{\circ} \mathrm{C}$ at $50 \mathrm{rpm}$ and incubated at different time intervals up to $4 \mathrm{~h}(0 \mathrm{~min}$ - control sample, $10 \mathrm{~min}, 20 \mathrm{~min}$, $40 \mathrm{~min}, 60 \mathrm{~min}, 120 \mathrm{~min}, 180 \mathrm{~min}$, and $240 \mathrm{~min}$ ). The order in which the samples were digested in vitro was randomised. Immediately after each digestion time, samples were neutralized using $0.5 \mathrm{M} \mathrm{NaHCO}_{3}$. Then SSP and FSP cubes were separated from the gastric juice using a sieve and then following $\beta$-carotene release, microstructural changes, textural and breakdown measurements of sweet potatoes cubes were measured.

\subsection{Light microscopy (LM)}

LM was done to determine the changes of the surface microstructure of SSP and FSP after gastric digestion. Samples were pre-fixed in Modified Karnovsky's Fixative (3\% Gluteraldehyde (v/v) 2\% Formaldehyde (w/v) in $0.1 \mathrm{M}$ Phosphate Buffer ( $\mathrm{pH}$ 7.2)) for at least $2 \mathrm{~h}$. The sample was then washed thrice, $10 \mathrm{~min}$ each, with $0.1 \mathrm{M}$ phosphate buffer ( $\mathrm{pH}$ 7.2) and secondarily fixed in 1\% Osmium Tetroxide in $0.1 \mathrm{M}$ phosphate buffer for $1 \mathrm{~h}$. Then, samples were rinsed again three times with $0.1 \mathrm{M}$ Phosphate Buffer ( $\mathrm{pH} 7.2)$ and dehydrated through a graded acetone series $(25 \%, 50 \%, 75 \%, 95 \%, 100 \%)$ for 10-15 min each, and three changes of $95 \%$ acetone for $10 \mathrm{~min}$ each, followed by two changes of $100 \%$ acetone for one hour each. The samples were then put into 50:50 resin:acetone and placed on the stirrer overnight. This was replaced by fresh $100 \%$ resin (Procure 812 , ProSciTech Australia) for $8 \mathrm{~h}$ on the stirrer. This step was repeated twice more (overnight in $100 \%$ resin, $8 \mathrm{~h}$ in $100 \%$ resin). Samples were then embedded in moulds with fresh resin and cured in a $60{ }^{\circ} \mathrm{C}$ oven for $48 \mathrm{~h}$. For the LM, sample sections were cut at $1 \mu \mathrm{m}$ using a glass knife on the ultramicrotome (Leica EM UC7, Germany) and heat fixed onto glass slides. These were stained with $0.05 \%$ Toluidine Blue for approximately $12 \mathrm{~s}$ and viewed under the light microscope (Zeiss Axiophot Microscope with Differential Interference Contrast Optics and Colour CCD camera, Germany).

\subsection{Analysis of $\beta$-carotene release during in vitro gastric digestion}

Fried and steamed sweet potato samples were subjected to simulated digestion (oral and gastric phase) as described in Section 2.3. Immediately after each digestion time, sweet potato samples were snap- 
frozen using liquid $\mathrm{N}_{2}$ and stored at $-80{ }^{\circ} \mathrm{C}$. Then, the dry matter content of digested samples was obtained by freeze-drying and powdered using a coffee grinder and passed through a $0.2 \mathrm{~mm}$ mesh. All samples were stored in dark conditions for analyses. The sample preparation procedure was also made in dim light.

The standard $\beta$-carotene stock solution at $1 \mathrm{mg} / \mathrm{mL}$ concentration was prepared by dissolving the standard in acetone. The working standard solutions of 16, 8, 4, 2, 1 and $0.50 \mu \mathrm{g} / \mathrm{mL}$ were prepared. All solutions were protected against the light with aluminium foil.

Remaining $\beta$-carotene was extracted from digested sweet potato samples as described by Biswas, Sahoo, and Chatli (2011). For $\beta$-carotene extraction, each $0.5 \mathrm{~g}$ of freeze-dried digested sweet potato sample was accurately weighed in a glass test tube. Then, $5 \mathrm{~mL}$ of acetone was added, and the tube was held for $15 \mathrm{~min}$ with occasional shaking, vortex at high speed for $10 \mathrm{~min}$, and finally centrifuged at $1370 \mathrm{~g}$ for $10 \mathrm{~min}$. The supernatant was collected into a separate test tube, and the remaining $ß$-carotene compound was re-extracted (until it gives a colourless residue) with $5 \mathrm{~mL}$ of acetone followed by centrifugation once again as above. Both of the supernatants were pooled together and then passed through the Whatman filter paper No. 42 into $25 \mathrm{~mL}$ volumetric flask. The carotenoid extract was then made up to $25 \mathrm{~mL}$ using acetone. The absorbance of the extract was determined at $449 \mathrm{~nm}$ wavelength in a UV-Vis spectrophotometer. A cuvette containing acetone was used as a blank to calibrate the spectrophotometer to the zero point. $\beta$-carotene release (\%) was calculated as follows:

$\beta$ - carotene release $\left.(\%)=\left(\beta_{0}-\beta_{t}\right) / \beta_{0}\right) \times 100$

where $\beta_{0}$ is initial $\beta$-carotene (Total $\beta$-carotene $\mu \mathrm{g} / \mathrm{g}$ dry matter) and $\beta_{t}$ is the remaining $\beta$-carotene content $(\mu \mathrm{g} / \mathrm{g}$ dry matter) after digestion time t.

\subsection{Hardness determination using texture profile analysis}

The texture profile analysis of digested steamed and fried sweet potatoes cubes was performed using a Texture Analyser TA-XTPlus (Texture Technologies, Stable Microsystems, Surrey, UK). One sweet potato cube was placed on the base plate of the TA-XTPlus with a cylindrical flat-end aluminium probe ( $35 \mathrm{~mm}$ in diameter) using a $50 \mathrm{~kg}$ load cell. The crosshead speed was $0.5 \mathrm{~mm} / \mathrm{s}$, with a rest period of $5 \mathrm{~s}$ between cycles and the deformation was set at $50 \%$ of the original length. The maximum force $(\mathrm{N})$ recorded during the compression measurement (peak force of the first compression cycle) is referred to as the hardness of the sample. Three separate replicates were performed for each cooking treatment (SSP and FSP) and digestion time point, and eight determinations were performed per replicate for each gastric digestion time.

\subsection{Weibull model parameters and softening half time determination}

The change in hardness was fit to the Weibull model, according to Bornhorst et al. (2015), using the following equation:

$\frac{\mathrm{H}_{\mathrm{t}}}{\mathrm{H}_{0}}=\mathrm{e}^{-\mathrm{kt}(\beta)}$

where $H_{t}$ is the hardness $(N)$ at time $t$; $H_{0}$ is the initial hardness $(N)$; $k$ is the scale parameter, which may indicate the rate of change in hardness $\left(\min ^{-1}\right)$; $t$ is the digestion time (min); and $\beta$ is the distribution shape factor (dimensionless). The goodness of fit between the experimental and predicted values was determined using the error sum of squares (SSE) and the coefficient of determination $\left(\mathrm{R}^{2}\right)$.

The softening halftime $\left(\mathrm{t}_{1 / 2}\right)$ was calculated as the time required for the initial hardness to be reduced by $50 \%$ using the following equation:

$\mathrm{t}_{\left(\frac{1}{2}\right)}=\left(\frac{-\ln 0.5}{\mathrm{k}}\right)^{\frac{1}{\beta}}$ where $\mathrm{k}$ is the scale parameter and $\beta$ is the distribution shape factor of Weibull model.

\subsection{Analysis of $\beta$-carotene release during mechanical disintegration of sweet potatoes using a human gastric simulator (HGS)}

The influence of gastric juice diffusion into the steamed and fried sweet potatoes cubes on their breakdown behaviour was analysed by treating the soaked samples in a dynamic HGS for $10 \mathrm{~min}$. The HGS mimics the mechanical and grinding forces within the human stomach (Ferrua \& Singh, 2015; Kong \& Singh, 2010). The latex stomach chamber was lined with a thin polyester mesh bag (pore size of the mesh bag is approximately $1 \mathrm{~mm}$ ), which permits only particle size of less than $1 \mathrm{~mm}$ to pass as a gastric digesta. A plastic tube was connected to the bottom of the stomach chamber in order to remove the gastric digesta (particles of size $<1 \mathrm{~mm}$ ) from the system during the digestion process. The peristaltic contractions on four sides of the latex stomach chamber were generated by six pairs of equally spaced rollers attached with the four conveyor belts. The mechanical contraction frequency was 3 times/min, mimicking the actual stomach peristalsis. The temperature inside the human gastric chamber was maintained at $37{ }^{\circ} \mathrm{C}$.

The method of operating the HGS was adapted from the procedures described by Guo et al. (2015). Steamed and fried sweet potatoes samples $(100 \mathrm{~g})$ were subjected to simulated static in vitro digestion (oral and gastric phase) as described in Section 2.3. Then, the digested sample with neutralized gastric juice was loaded into the stomach chamber. For control sample ( 0 min digestion), steamed and fried sweet potatoes samples ( $100 \mathrm{~g}$ ) were directly loaded into the HGS, and instead of neutralized gastric juice, an equal amount of water was added into the stomach chamber. The samples were exposed to the mechanical forces applied by the HGS for $10 \mathrm{~min}$ and then, gastric digesta were removed from the bottom of the stomach, manually.

Immediately after each digestion time, the digesta sample retained in the simulated latex stomach chamber was removed. These samples were snap-frozen using liquid $\mathrm{N}_{2}$ and stored at $-80{ }^{\circ} \mathrm{C}$. Subsequent $\beta$ carotene extraction and analysis were carried out as described in the Section 2.5.

\subsection{Statistical analysis}

An ANOVA was conducted using a 2-factor factorial design to determine differences in hardness $(\mathrm{N})$ and $\beta$-carotene release during in vitro gastric digestion. The factors were cooking treatment (SSP and FSP), and digestion time (0-240 min). Tukey test was used to analyse the differences between means and statistical significance was assessed at a level of $\mathrm{p}<0.05$. The Student $t$-test was used to assess differences in the Weibull model parameters and softening half time. Minitab 17 software was used for statistical analysis.

\section{Results and discussion}

\subsection{Selection of experimental parameters}

The size of the sweet potatoes cubes was selected to be $5 \mathrm{~mm}$ in length, width and thickness, which is similar to the upper limit of the actual size range of vegetable particles after oral mastication (JalabertMalbos, Mishellany-Dutour, Woda, \& Peyron, 2007). In order to quantify textural changes during digestion, the upper fragment size limit after oral mastication was chosen to ensure that the sweet potato samples did not completely break down during the $4 \mathrm{~h}$ of gastric digestion. In addition, a simple geometry (cubes) was selected to limit possible variation of textural measurements.

In this study, $4 \mathrm{~h}$ of digestion time was selected because most solid foods are cleared from the human stomach approximately within 3-4 h (Minekus et al., 2014). Moreover, the HGS test used in this study was not intended to reproduce the actual physicochemical reactions that 


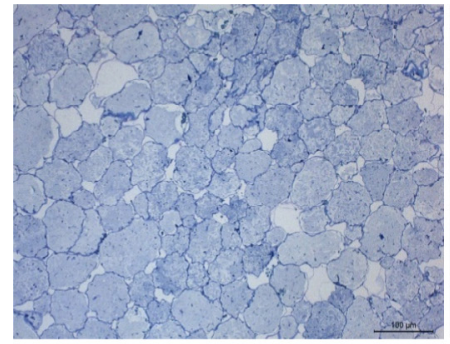

(a) $0 \mathrm{~min}$

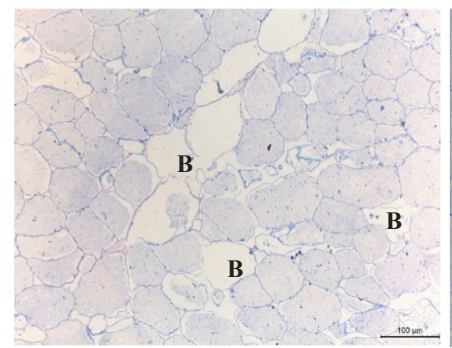

(e) $60 \mathrm{~min}$

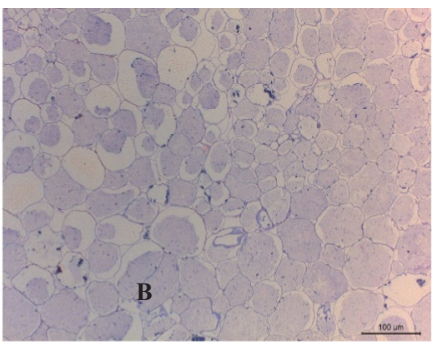

(b) $10 \mathrm{~min}$

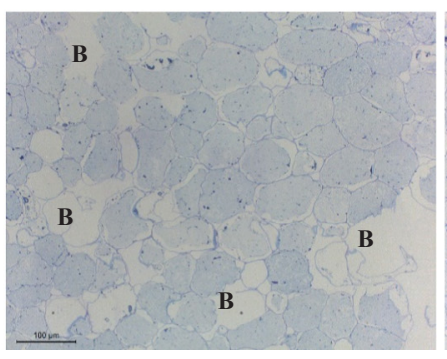

(f) $120 \mathrm{~min}$

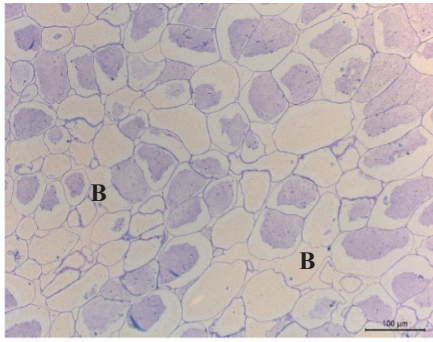

(c) $20 \mathrm{~min}$

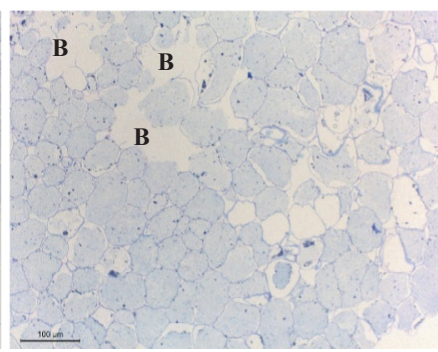

(g) $180 \mathrm{~min}$

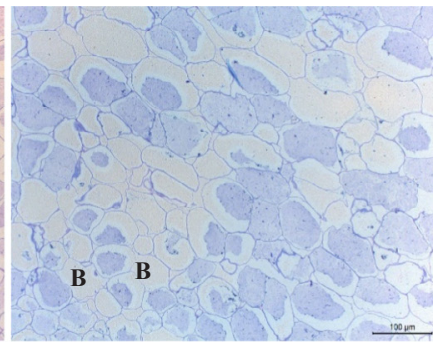

(d) $40 \mathrm{~min}$

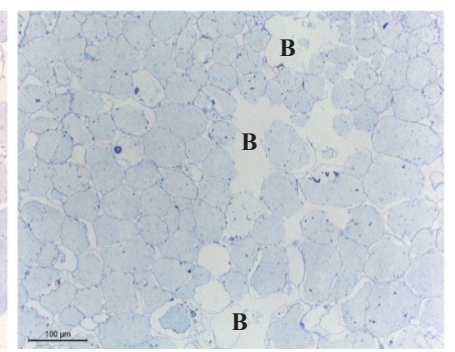

(h) $240 \mathrm{~min}$

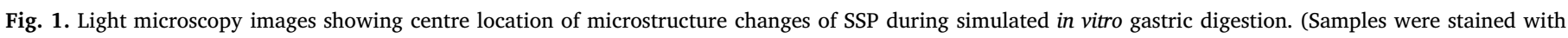

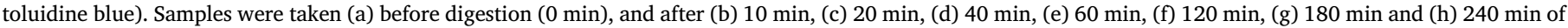

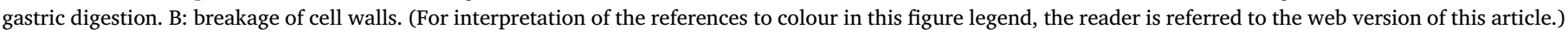

develop during digestion, but to provide an initial framework to characterise the influence of gastric juice on the ß-carotene release of the sweet potato samples. Soaked steamed/fried sweet potato cube samples were exposed to the mechanical forces generated by the HGS for $10 \mathrm{~min}$, because of preliminary studies which indicated that more than $10 \mathrm{~min}$ in the HGS resulted in fine debris of all the end-products, whereas less than 10 min left many particles undamaged. For the LM, toluidine blue dye was used because it is a basic dye with high affinity for acidic tissue components that stains polysaccharides purple (Sridharan \& Shankar, 2012).

\subsection{Cellular structure of the cooked sweet potatoes is influenced by the in vitro gastric digestion}

LM was used to observe the microstructural changes of the crosssections of steamed and fried sweet potato cubes after simulated gastric digestion. Figs. 1-4 show the centre and surface of SSP and FSP samples, respectively.

SSP parenchyma cells (Figs. 1(a) and 2(a)) were observed to be completely filled with gelatinised starch matrix after steaming, which is in agreement with the results reported by a previous study (Bordoloi, Kaur, \& Singh, 2012). The images in fried samples (Figs. 3(a) and 4(a)) show that the cells are more separated and cell arrangement was extensively disrupted. As a result, the volume of the intercellular space increased and oil accumulated in intercellular spaces after frying compared to the SSP. Thus, the microstructure of sweet potatoes is significantly influenced by the method of cooking/processing, even before digestion has started. Changes in the mechanical properties and integrity of cell walls of potato and sweet potato tubers during cooking are mainly attributed to the changes affecting cell wall and middle lamella components (Bordoloi et al., 2012; Tian et al., 2016). The middle lamella is mainly composed of pectin (structural heteropolysaccharide) that has been reported to degrade during thermal processing (Bordoloi et al., 2012).

Although the cooked sweet potato cubes remained visually intact and do not completely break down after $4 \mathrm{~h}$ of static in vitro gastric digestion, LM images demonstrate that the microstructure of sweet potatoes is significantly influenced by simulated gastric digestion. All of these digested steamed and fried sweet potato samples show that before digestion, the cells are complete and without breakage, however after diffusion of gastric juice, cell wall breakage can be observed in the centre (Figs. 1 and 3) and surface locations (Figs. 2 and 4) of both SSP (Figs. 1 and 2) and FSP (Figs. 3 and 4). More broken cells and empty cells can be observed in the surface area of both steamed and fried sweet potatoes compared to the centre, which is fitting given that the surface area is the first site that comes into contact with gastric juice (Figs. 2 and 4). These figures also demonstrate that intracellular solid contents including $\beta$-carotene within the first few surface cellular layers were lost during digestion (Figs. 2 and 4). However, there is the possibility of some artefacts produced due to the sweet potato sample preparation for the microscopy analysis. FSP showed very limited cell wall degradation in the centre of digested cubes after simulated gastric digestion (Fig. 3) compared with SSP (Fig. 1). However, gaps between cells and more intercellular and intracellular spaces can be observed after digestion in FSP, which may be due to the looser structure of fried potatoes than steamed ones.

\subsection{Microstructural differences between steamed and fried sweet potatoes} did not result in different $\beta$-carotene release under the sole acidic and enzymatic degradations

The initial $ß$-carotene content differed with cooking method from $381 \pm 19 \mu \mathrm{g} / \mathrm{g}$ dry matter in SSP to $335 \pm 15 \mu \mathrm{g} / \mathrm{g}$ dry matter in FSP. In frying samples, frying temperature $\left(180^{\circ} \mathrm{C}\right)$ may reduce $\beta$-carotene content because $ß$-carotene degrades when exposed to long preparation times and high temperatures (Howard, Wong, Perry, \& Klein, 1999). Studies showed that sweet potatoes processing methods prior to consumption may significantly reduce the amount of remaining $\beta$-carotene that is available for release and absorption in the human gastro-intestinal tract but increased its bioaccessibility (Tumuhimbise et al., 2009). Several studies have shown that in plant-food matrices, carotenoids occur as membrane-bound semi-crystalline structures within the cells and heat treatments could increase the bioavailability of carotenoids by disrupting or softening plant cells and carotenoids-protein complexes (Lemmens, Van Buggenhout, Van Loey, \& Hendrickx, 2010).

Fig. 5 shows the $\beta$-carotene release profiles of the steamed and fried sweet potatoes during simulated gastric digestion. As expected, digestion time significantly ( $\mathrm{p}<0.05$ ) influenced the total amount of $\beta$ carotene released, but $\beta$-carotene release was not statistically ( $\mathrm{p}>0.05$ ) influenced by the cooking method; the interaction 


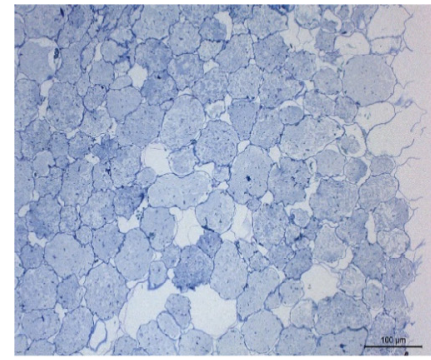

(a) $0 \mathrm{~min}$

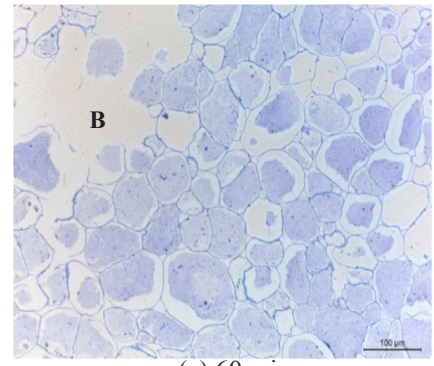

(e) $60 \mathrm{~min}$

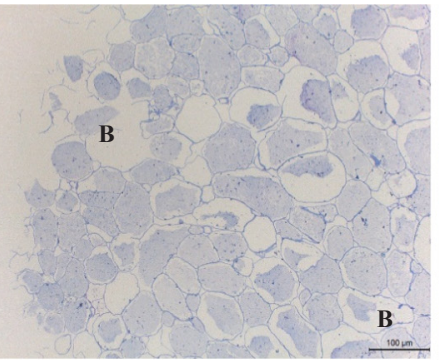

(b) $10 \mathrm{~min}$

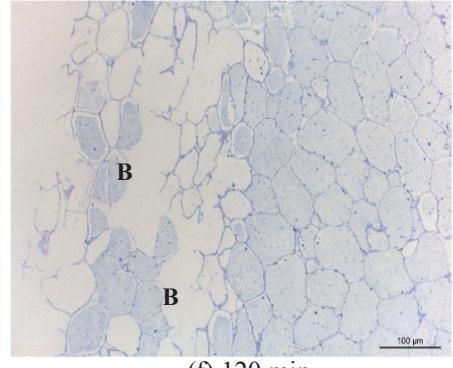

(f) $120 \mathrm{~min}$

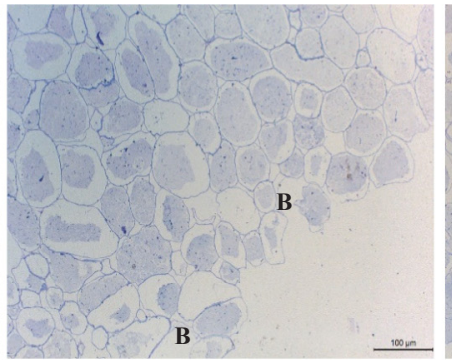

(c) $20 \mathrm{~min}$

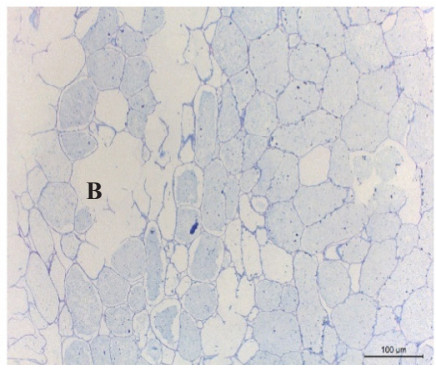

(g) $180 \mathrm{~min}$

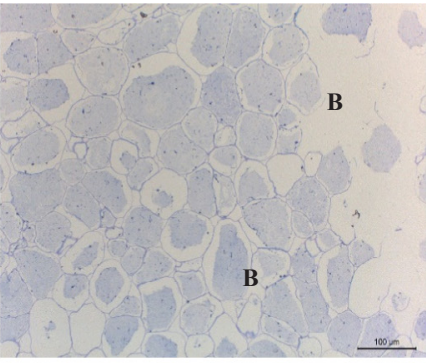

(d) $40 \mathrm{~min}$

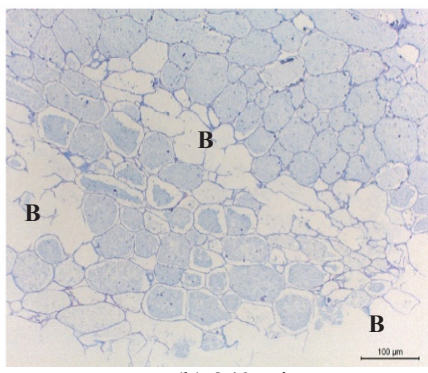

(h) $240 \mathrm{~min}$

Fig. 2. Light microscopy images showing surface location of microstructure changes of SSP during simulated in vitro gastric digestion. (Samples were stained with toluidine blue). Samples were taken (a) before digestion (0 min), and after (b) $10 \mathrm{~min}$, (c) $20 \mathrm{~min}$, (d) $40 \mathrm{~min}$, (e) $60 \mathrm{~min}$, (f) $120 \mathrm{~min}$, (g) $180 \mathrm{~min}$ and (h) $240 \mathrm{~min}$ of gastric digestion. B: breakage of cell walls. (For interpretation of the references to colour in this figure legend, the reader is referred to the web version of this article.)

digestion time $\times$ cooking method was not significant. Both steamed and fried sweet potatoes had a similar total $\beta$-carotene loss percentage at the end of $4 \mathrm{~h}$ of gastric digestion $(17.6 \pm 3.3 \%$ and $18.3 \pm 0.7 \%$, respectively).

Considering the findings of the Section 3.2, which revealed that more intercellular and intracellular spaces can be observed in FSP than in SSP, it may be speculated that gastric juice penetrates into FSP faster than into SSP, as previously reported (Somaratne et al., 2019). Yet, the present results indicate that the difference in the initial microstructure of the cooked sweet potatoes, the different rate of hydrochloric acid diffusion and the different effect on the microstructure during digestion did not affect the release of $\beta$-carotene. These results indicate that in the absence of mechanical forces normally undertaken in the human stomach, $\beta$-carotene release from sweet potato food matrix during gastric digestion may be largely independent of the different structure between steamed and fried samples.

As shown in results from microstructure analysis (Section 3.2), the majority of the cells located in the centre of the sweet potato cubes stayed intact after $4 \mathrm{~h}$ of static in vitro gastric digestion. Thus, acid hydrolysis of the cellular structure had a great effect on the breakdown

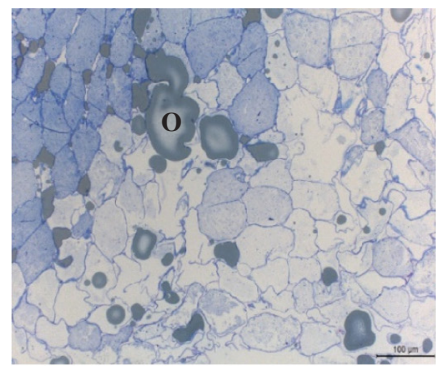

(a) $0 \mathrm{~min}$

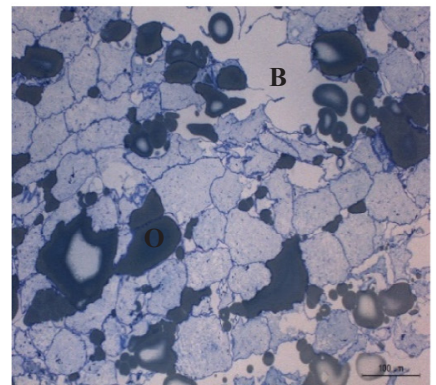

(e) $60 \mathrm{~min}$

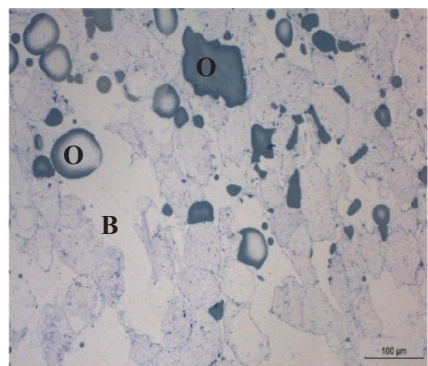

(b) $10 \mathrm{~min}$

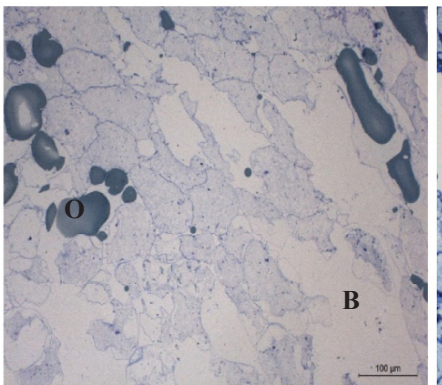

(f) $120 \mathrm{~min}$

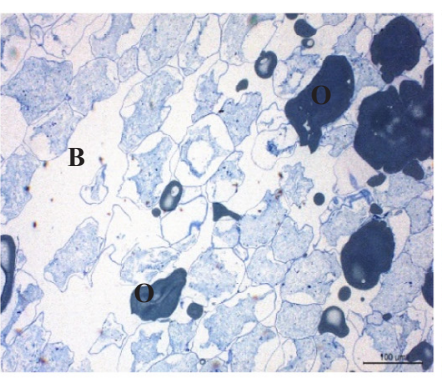

(c) $20 \mathrm{~min}$

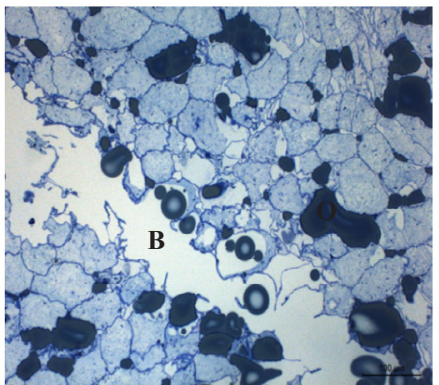

(g) $180 \mathrm{~min}$

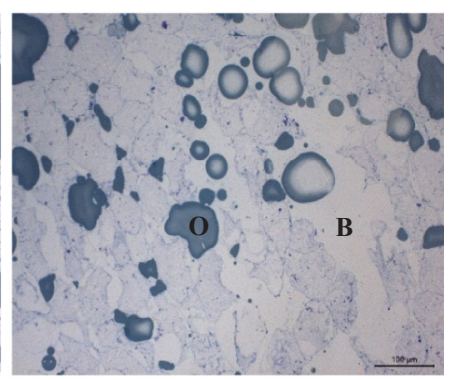

(d) $40 \mathrm{~min}$



(h) $240 \mathrm{~min}$

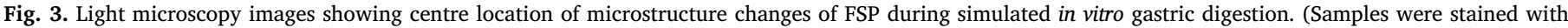

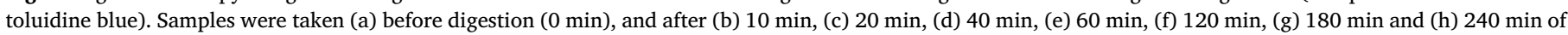

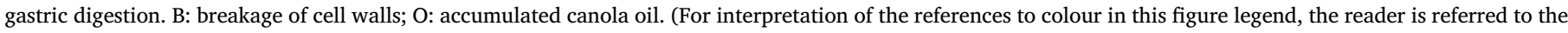
web version of this article.) 


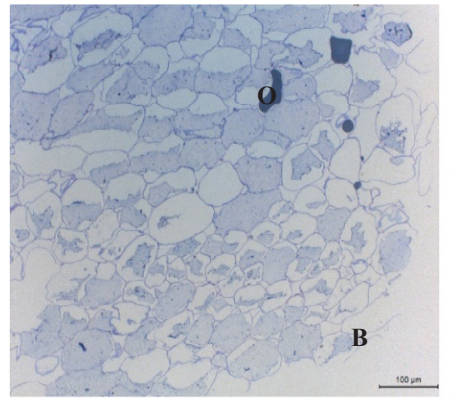

(a) $0 \mathrm{~min}$

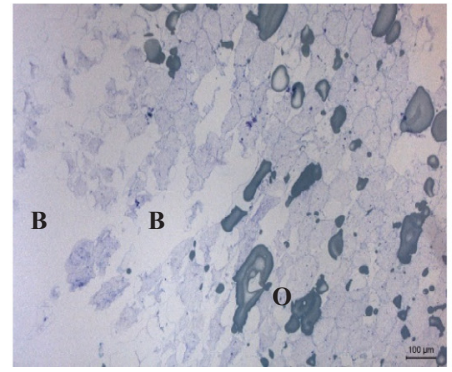

(e) $60 \mathrm{~min}$

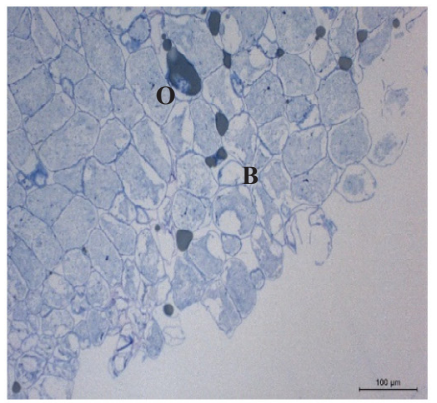

(b) $10 \mathrm{~min}$

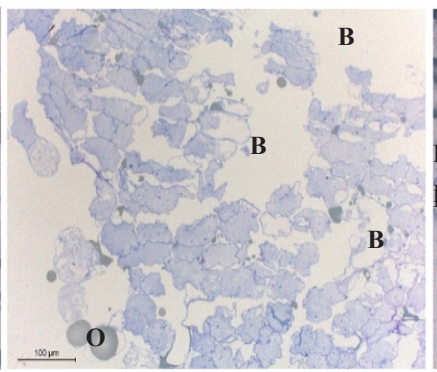

(f) $120 \mathrm{~min}$

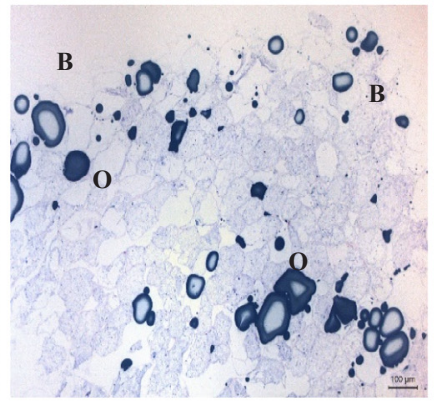

(c) $20 \mathrm{~min}$

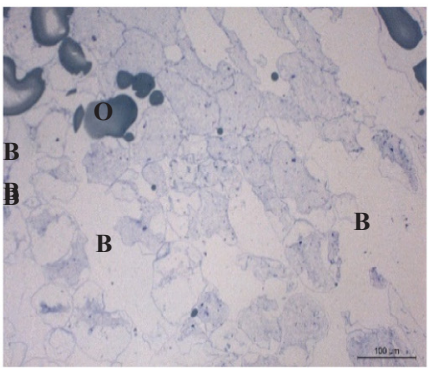

(g) $180 \mathrm{~min}$

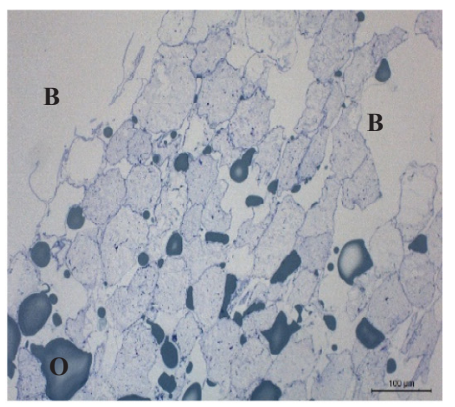

(d) $40 \mathrm{~min}$



(h) $240 \mathrm{~min}$

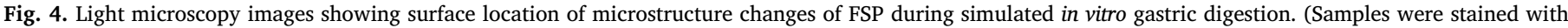

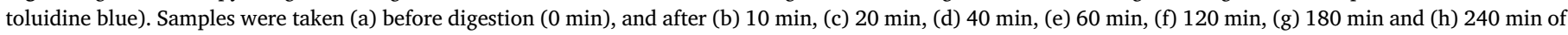

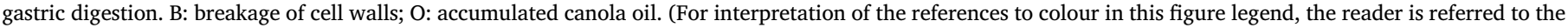
web version of this article.)

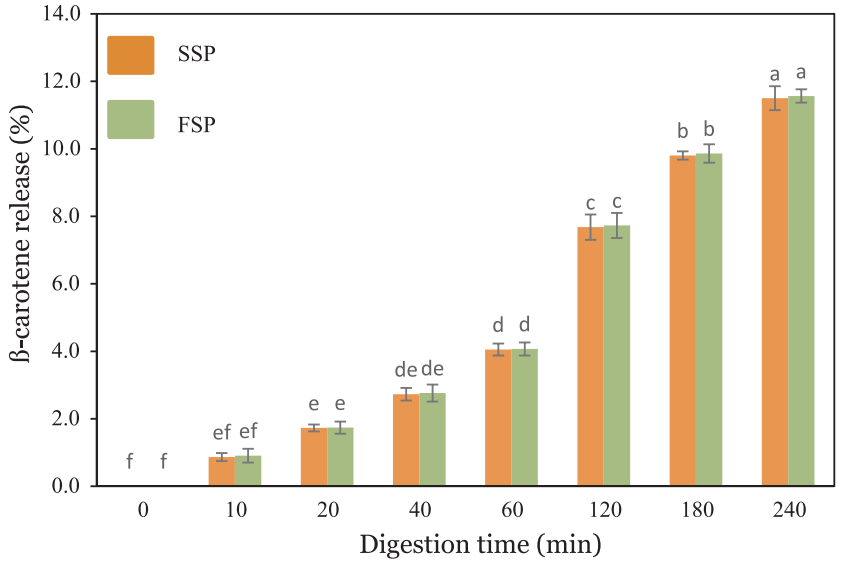

Fig. 5. ß-carotene release (\%) profiles of the SSP and FSP matrices as a result of biochemical degradation during simulated in vitro gastric digestion. Values are given as the means $\pm \mathrm{SD}(\mathrm{n}=3)$. Different letters correspond to significant differences $(\mathrm{p}<0.05)$ as determined using multiple comparisons of means (Tukey test).

of cell walls only in the surface of the samples, which is the first site that enter into contact with gastric juice and probably on the release of $\beta$ carotene from the surface cells in both steamed and fried sweet potatoes. Nevertheless, the cell wall in the centre of the sweet potato matrix may act as a physical 'barrier' towards the action of gastric acid and to the release of $ß$-carotene into the gastric digesta. The microscopic observations also suggest that in the fried samples, although the gastric acid rapidly diffuses into the food matrix as described in Somaratne et al. (2019), gastric juice is not entering the cells due to the fact that accumulated canola oil around the cell walls may inhibit the degradation of cell walls by gastric acid. This finding is supported by the previous study of Mennah-Govela and Bornhorst (2016b). This observation is in agreement with both steamed and fried samples having a similar rate of $ß$-carotene release during static in vitro gastric digestion.
3.4. Softening during gastric phase is faster and more significant in fried sweet potatoes than in steamed sweet potatoes

The hardness (peak force of the first compression cycle in $\mathrm{N}$ ) of the steamed and fried sweet potato matrices during simulated gastric digestion is shown in Table 1. Changes in the hardness of the sweet potato cubes during digestion were significantly influenced by the cooking method (SSP or FSP) and digestion time ( $\mathrm{p}<0.05)$. Textural changes occurring during thermal processing and digestion in carbohydratebased plant foods (i.e. potatoes and rice) are mainly associated with the gelatinisation behaviour of starch and degradation of cell wall and middle lamellae structural components (Mennah-Govela \& Bornhorst, 2016a, 2016b).

Initial ( $0 \mathrm{~min}$ ) hardness measured in FSP was not significantly different from the corresponding SSP $(\mathrm{p}>0.05)$. The similarity in measured hardness may appear to contradict the different microstructural changes of sweet potatoes after these two cooking methods as observed through LM (Section 3.2). SSP parenchyma cells were observed to be completely filled with gelatinised starch matrix after steaming. In contrast, the interior microstructure of fried samples

Table 1

Changes in the hardness $(\mathrm{N})$ of the steamed and fried sweet potatoes during in vitro gastric digestion.

\begin{tabular}{lll}
\hline Digestion time (min) & Hardness of SSP $(\mathrm{N})^{*}$ & Hardness of FSP $(\mathrm{N})^{*}$ \\
\hline 0 & $4.6 \pm 0.2^{\mathrm{ab}}$ & $4.8 \pm 0.4^{\mathrm{a}}$ \\
10 & $4.5 \pm 0.3^{\mathrm{ab}}$ & $4.3 \pm 0.2^{\mathrm{abc}}$ \\
20 & $4.5 \pm 0.1^{\mathrm{ab}}$ & $4.0 \pm 0.1^{\mathrm{bc}}$ \\
40 & $4.3 \pm 0.1^{\mathrm{abc}}$ & $3.9 \pm 0.4^{\mathrm{bcd}}$ \\
60 & $4.1 \pm 0.3^{\mathrm{bc}}$ & $3.8 \pm 0.2^{\mathrm{d}}$ \\
120 & $3.8 \pm 0.3^{\mathrm{cd}}$ & $3.0 \pm 0.1^{\mathrm{ef}}$ \\
180 & $3.4 \pm 0.1^{\mathrm{de}}$ & $2.4 \pm 0.3^{\mathrm{fg}}$ \\
240 & $2.9 \pm 0.3^{\mathrm{ef}}$ & $2.0 \pm 0.0^{\mathrm{g}}$ \\
\hline
\end{tabular}

* Values are means \pm SD $(n=24)$. Different letters within each column and row represent statistically different means $(\mathrm{p}<0.05)$. SSP: Steamed sweet potatoes. FSP: Fried sweet potatoes. 
showed that the cells were more separated and cell arrangement was extensively disrupted, which may be expected to lower the initial hardness of fried sweet potatoes compared to SSP. However, since the fried sweet potato interior microstructure is porous, the high initial hardness of the fried sweet potato is likely due to the crust formation during frying (Farinu \& Baik, 2007).

As seen in Table 1, the hardness of steamed and fried sweet potatoes significantly decreased during digestion time $(\mathrm{p}<0.05)$. After 240 min of digestion, FSP exhibited the greatest decrease (58\%) compared to its initial hardness value, whereas only a $37 \%$ decrease in hardness was observed in the case of SSP. During the first hour of gastric digestion, the hardness of the FSP decreased significantly from $4.8 \pm 0.4 \mathrm{~N}$ to $3.8 \pm 0.2 \mathrm{~N}$ ( $22 \%$ of change). The rapid decrease of hardness in FSP during digestion may be associated with the rapid softening of the crust (Somaratne et al., 2019). Furthermore, the disrupted structure and high porosity developed during frying process lead to a rapid loss of the firmness and integrity of cell walls of FSP after absorption of gastric juice as observed in light micrographs (see the Section 3.2). Similar rapid decreases in hardness were not observed in the SSP.

The Weibull distribution function is widely used to describe the softening kinetics of solid foods during static in vitro gastric digestion (Bornhorst et al., 2015; Drechsler \& Bornhorst, 2018). The softening curves (Fig. 6) determined by monitoring changes in steamed and fried sweet potatoes hardness during digestion fit well to the Weibull model (Eq. (2)), as evidenced by the high $\mathrm{R}^{2}$ values (0.97-0.99, Table 2 ) and low SSE $(<0.002$, Table 2$)$. The reported softening rate constants of the Weibull function (k) demonstrated that the FSP showed higher rate of softening $\left(\mathrm{k}=0.004 \mathrm{~min}^{-1}\right)$ compared to SSP $\left(\mathrm{k}=0.002 \mathrm{~min}^{-1}\right)$. The $\beta$ value of the SSP is very close to one than FSP, indicating a quite linear decrease in the hardness of SSP with digestion time.

The half time $\left(\mathrm{t}_{1 / 2}\right)$, defined as the time to reach $50 \%$ reduction in initial hardness incorporates both the $\mathrm{k}$ and $\beta$ parameters from the Weibull model, and thus describes the overall curve properties more appropriately than either one of the fitted parameters on its own (Bornhorst et al., 2015). Results revealed that while no significant differences $(\mathrm{p}>0.05)$ were observed between the initial hardness of the steamed and fried samples $(4.6 \pm 0.2 \mathrm{~N}$ and $4.8 \pm 0.4 \mathrm{~N}$, respectively), the softening half time varied from $381 \pm 97$ (SSP) to $218 \pm 32 \mathrm{~min}$ (FSP). Thus, foods with similar initial hardness may not have comparable softening rates, as previously observed by Bornhorst et al. (2015). The differences in the softening half time observed between the steamed and fried sweet potatoes tested may be attributed to their initial microstructure as well as the rate of acid diffusion. In FSP, the porous microstructure leads to more rapid acid diffusion and



Fig. 6. Softening curves of the steamed and fried sweet potatoes matrices during in vitro gastric digestion based on the hardness $(\mathrm{N})$ measurements. Values are given as averages $(n=3)$ with error bars as SD (some are too small to be visible). The solid lines represent the predicted values from the average Weibull model parameters shown in Table 2. SSP: Steamed sweet potatoes. FSP: Fried sweet potatoes.
Table 2

Parameter values of Weibull function (Eq. (2)) fitted to the softening curves of the steamed and fried sweet potatoes during in vitro gastric digestion.

\begin{tabular}{llllll}
\hline & $\mathrm{k}$ & $\mathrm{R}$ & $\mathrm{R}^{2}$ & $\mathrm{SSE}$ & $\mathrm{t}_{1 / 2}(\min )$ \\
\hline SSP & $0.002 \pm 0.00^{\mathrm{b}}$ & $0.99 \pm 0.02^{\mathrm{a}}$ & 0.99 & 0.000 & $381 \pm 97^{\mathrm{a}}$ \\
FSP & $0.004 \pm 0.00^{\mathrm{a}}$ & $0.91 \pm 0.07^{\mathrm{a}}$ & 0.97 & 0.002 & $218 \pm 32^{\mathrm{b}}$ \\
\hline
\end{tabular}

$\mathrm{k}$ is the rate of change in hardness $\left(\mathrm{min}^{-1}\right)$.

$\beta$ is the distribution shape factor (dimensionless).

$\mathrm{R}^{2}$ is the goodness of fit; SSE is error sum of squares.

$\mathrm{t}_{1 / 2}$ is the softening half-time ( $\mathrm{min}$ ).

SSP: Steamed sweet potatoes and FSP: Fried sweet potatoes.

Values represent the average model parameters or softening half time from 3 digestion trials $\pm \mathrm{SD}$.

Means within each column followed by different superscript letters are significantly different $(\mathrm{p}<0.05)$.

subsequent collapse as well as faster softening during in vitro gastric digestion compared to the compact and denser structure of SSP, which is in agreement with previous findings (Somaratne et al., 2019). The relevance of these findings on the breakdown response of the sweet potatoes samples is discussed in the following sections.

\subsection{Microstructural differences between steamed and fried sweet potatoes} result in different $\beta$-carotene release when biochemical and mechanical degradations are combined

Fig. 7 shows the $\beta$-carotene release profiles of the steamed and fried sweet potatoes, when they were exposed to gastric juice absorption over 240 min during static in vitro gastric phase and subsequent mechanical disintegration in the HGS. As expected, digestion time significantly ( $\mathrm{p}<0.05$ ) increased the total amount of $\beta$-carotene released from both steamed and fried sweet potatoes. Moreover, there is a trend of higher $\beta$-carotene release from the FSP than from the SSP at each and every digestion point. In the Section 3.3, it was shown that, in the absence of mechanical forces, $\beta$-carotene release from the sweet potato food matrices during static in vitro gastric digestion was not affected by the different structures in steamed and fried samples (nearly $12 \%$ release of $\beta$-carotene from both SSP and FSP, at the end of $4 \mathrm{~h}$ of gastric digestion). In contrast, in the presence of mechanical forces of the human gastric simulator, applied after static in vitro gastric digestion, $\beta$ carotene release from the sweet potato food matrices might be influenced by the initial microstructure of steamed and fried samples (nearly $35 \%$ and $40 \%$ release of $\beta$-carotene from SSP and FSP, respectively, at the end of $4 \mathrm{~h}$ of gastric digestion). Thus, mechanical forces such as those generated by the human stomach, had a greater effect on the breakdown of cell walls and the subsequent release of $ß$-carotene entrapped within cells in both steamed and fried sweet potatoes.

There is a trend of faster release of $\beta$-carotene in FSP than in SSP when they were exposed to gastric juice (biochemical effects) during static in vitro gastric phase and subsequent mechanical disintegration in the HGS (Fig. 7). We have already described that gaps between cells and more intercellular and intracellular spaces can be observed after digestion of FSP (Section 3.2) and as a result, gastric juice penetrates this food matrix faster than SSP (Somaratne et al., 2019). Thus, fried matrix underwent collapse as well as quickest softening during in vitro gastric digestion compared to the compact and denser structure of SSP, which may lead to the faster disintegration and subsequent $\beta$-carotene release in the HGS. This is in line with the results of Tumuhimbise et al. (2009), who showed that the FSP had the highest percentage of bioaccessible all-trans- $\beta$-carotene compared to SSP during in vitro dynamic digestion. These authors also highlighted that the presence of fat in the FSP may improve the bioaccessibility of fat-soluble $\beta$-carotene. Similarly, using a dynamic in vitro digestion model, Van Loo-Bouwman et al. (2014) highlighted that the bioaccessibility of $\beta$-carotene was two times higher in the oil-based diet compared to the vegetable based-mixed diet. These 


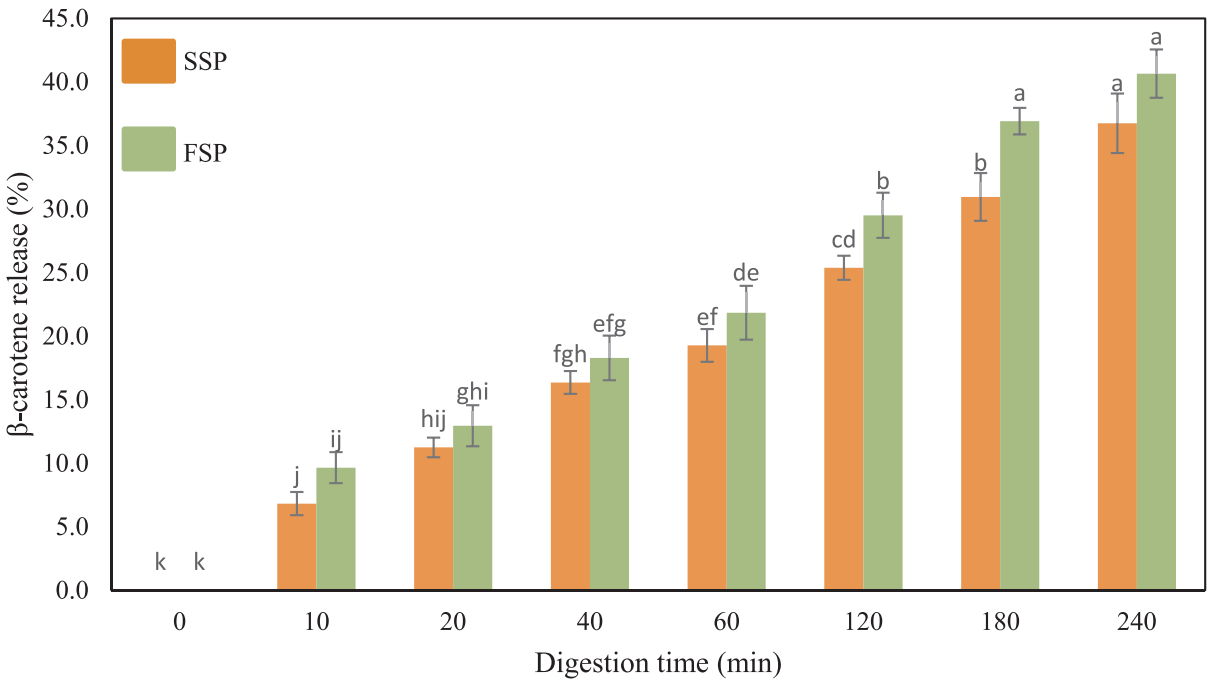

Fig. 7. ß-carotene release (\%) profiles of the steamed (SSP) and fried (FSP) sweet potato matrices along in vitro gastric digestion combined with mechanical forces in the human gastric simulator. Values are given as the means \pm SD $(n=3)$. Different letters correspond to significant differences ( $\mathrm{p}<0.05$ ) as determined using multiple comparisons of means (Tukey test). trends in the $\beta$-carotene release may correspond to the structural changes and softening kinetics observed through texture analysis (Sections 3.2 and 3.4).

\section{Conclusions}

Steamed and fried sweet potatoes microstructure play an important role in the food matrix softening, disintegration as well as the release of $\beta$ carotene during in vitro gastric digestion. It is important to note that gastric juice alone had no major effect on the complete breakdown of steamed/fried sweet potato cell walls even after $4 \mathrm{~h}$ of gastric digestion. In the absence of mechanical forces generated by the stomach, biochemical digestion did not have a great effect on the breakdown of cell walls and the release of $\beta$-carotene in steamed or fried sweet potato is similar. The microscopic observations also highlighted that, in the fried samples, gastric juice rapidly diffused into the porous food matrix, but did not enter the cells, possibly due to the accumulated canola oil around the cell walls inhibiting the degradation of the cell walls by the gastric juice. Thus, gastric juice content including acid, moisture and pepsin, may not have a major influence on digestion and release of nutrients from carbohydrate-based foods.

Frying caused a disruption of cell arrangement and the creation of a porous network whereas steaming produced a compact and denser structure. Thus, FSP matrix underwent quicker softening and collapse during in vitro gastric digestion compared to the compact and denser structure of SSP. This may lead to the faster cell wall breakdown and subsequent $\beta$-carotene release from FSP cellular matrix than SSP in the presence of the mechanical forces of the human stomach.

\section{CRediT authorship contribution statement}

Geeshani Somaratne: Conceptualization, Investigation, Resources, Visualization, Writing - original draft. Aiqian Ye: Supervision, Conceptualization. Francoise Nau: Supervision, Conceptualization. Maria J. Ferrua: Supervision, Conceptualization. Didier Dupont: Supervision, Conceptualization. R. Paul Singh: Supervision, Conceptualization. Jaspreet Singh: Funding acquisition, Supervision, Project administration, Conceptualization.

\section{Declaration of Competing Interest}

The authors declare that they have no known competing financial interests or personal relationships that could have appeared to influence the work reported in this paper.

\section{Acknowledgement}

The authors express gratitude to the Manawatu Microscopy and Imaging Centre, Massey University, New Zealand for carrying out the microscopy.

\section{References}

Bengtsson, A., Brackmann, C., Enejder, A., Alminger, M. L., \& Svanberg, U. (2010). Effects of thermal processing on the in vitro bioaccessibility and microstructure of $\beta$-carotene in orange-fleshed sweet potato. Journal of Agricultural and Food Chemistry, 58(20), 11090-11096.

Biswas, A., Sahoo, J., \& Chatli, M. (2011). A simple UV-Vis spectrophotometric method for determination of $\beta$-carotene content in raw carrot, sweet potato and supplemented chicken meat nuggets. LWT-Food Science and Technology, 44(8), 1809-1813.

Bordoloi, A., Kaur, L., \& Singh, J. (2012). Parenchyma cell microstructure and textural characteristics of raw and cooked potatoes. Food Chemistry, 133(4), 1092-1100.

Bornhorst, G. M., Ferrua, M. J., \& Singh, R. P. (2015). A proposed food breakdown classification system to predict food behavior during gastric digestion. Journal of Food Science, 80(5), R924-R934.

Drechsler, K, C, \& Ferrua, M, J (2016). Modelling the breakdown mechanics of solid foods during gastric digestion. Food Research International, 88, 181-190.

Drechsler, K. C., \& Bornhorst, G. M. (2018). Modeling the softening of carbohydrate-based foods during simulated gastric digestion. Journal of Food Engineering, 222, 38-48.

Farinu, A., \& Baik, O. D. (2007). Heat transfer coefficients during deep fat frying of sweetpotato: Effects of product size and oil temperature. Food Research International, 40(8), 989-994.

Ferrua, M. J., \& Singh, R. P. (2015). Human gastric simulator (Riddet Model): The impact of food bioactives on health. Cham: Springer61-71.

Guo, Q., Ye, A., Lad, M., Dalgleish, D., \& Singh, H. (2014). Effect of gel structure on the gastric digestion of whey protein emulsion gels. Soft Matter, 10(8), 1214-1223.

Guo, Q., Ye, A., Lad, M., Ferrua, M., Dalgleish, D., \& Singh, H. (2015). Disintegration kinetics of food gels during gastric digestion and its role on gastric emptying: An in vitro analysis. Food \& Function, 6(3), 756-764.

Howard, L., Wong, A., Perry, A., \& Klein, B. (1999). ß-Carotene and ascorbic acid retention in fresh and processed vegetables. Journal of Food Science, 64(5), 929-936.

Islam, S. N., Nusrat, T., Begum, P., \& Ahsan, M. (2016). Carotenoids and $\beta$-carotene in orange-fleshed sweet potato: A possible solution to vitamin A deficiency. Food Chemistry, 199, 628-631.

Jalabert-Malbos, M. L., Mishellany-Dutour, A., Woda, A., \& Peyron, M. A. (2007). Particle size distribution in the food bolus after mastication of natural foods. Food Quality and Preference, 18(5), 803-812.

Kong, F., \& Singh, R. P. (2008). Disintegration of solid foods in human stomach. Journal of Food Science, 73(5), R67-R80.

Kong, F., \& Singh, R. P. (2009a). Digestion of raw and roasted almonds in simulated gastric environment. Food Biophysics, 4(4), 365-377.

Kong, F., \& Singh, R. P. (2009b). Modes of disintegration of solid foods in simulated gastric environment. Food Biophysics, 4(3), 180-190.

Kong, F., \& Singh, R. P. (2010). A human gastric simulator (HGS) to study food digestion in human stomach. Journal of Food Science, 75(9), E627-E635.

Le Feunteun, S., Barbé, F., Rémond, D., Ménard, O., Le Gouar, Y., Dupont, D., \& Laroche, B. (2014). Impact of the dairy matrix structure on milk protein digestion kinetics: mechanistic modelling based on mini-pig in vivo data. Food and Bioprocess Technology, 7(4), 1099-1113.

Lemmens, L., Van Buggenhout, S., Van Loey, A. M., \& Hendrickx, M. E. (2010). Particle size reduction leading to cell wall rupture is more important for the $\beta$-carotene bioaccessibility of raw compared to thermally processed carrots. Journal of 
Agricultural and Food Chemistry, 58(24), 12769-12776.

Low, D. Y., D'Arcy, B., \& Gidley, M. J. (2015). Mastication effects on carotenoid bioaccessibility from mango fruit tissue. Food Research International, 67, 238-246.

Mennah-Govela, Y. A., \& Bornhorst, G. M. (2016a). Acid and moisture uptake in steamed and boiled sweet potatoes and associated structural changes during in vitro gastric digestion. Food Research International, 88, 247-255.

Mennah-Govela, Y. A., \& Bornhorst, G. M. (2016b). Mass transport processes in orange fleshed sweet potatoes leading to structural changes during in vitro gastric digestion. Journal of Food Engineering, 191, 48-57.

Minekus, M., Alminger, M., Alvito, P., Ballance, S., Bohn, T., Bourlieu, C., ... Brodkorb, A. (2014). A standardised static in vitro digestion method suitable for food-An international consensus. Food \& Function, 5(6), 1113-1124.

Schweiggert, R. M., Kopec, R. E., Villalobos-Gutierrez, M. G., Högel, J., Quesada, S., Esquivel, P., ... Carle, R. (2014). Carotenoids are more bioavailable from papaya than from tomato and carrot in humans: A randomised cross-over study. British Journal of Nutrition, 111(3), 490-498.

Singh, H., Ye, A., \& Ferrua, M. J. (2015). Aspects of food structures in the digestive tract. Current Opinion in Food Science, 3, 85-93.

Somaratne, G., Ferrua, M. J., Ye, A., Nau, F., Floury, J., Dupont, D., \& Singh, J. (2020a). Food material properties as determining factors in nutrient release during human gastric digestion: a review. Critical Reviews in Food Science and Nutrition, 1-17.

Somaratne, G., Nau, F., Ferrua, M. J., Singh, J., Ye, A., Dupont, D., ... Floury, J. (2020b).
In-situ disintegration of egg white gels by pepsin and kinetics of nutrient release followed by time-lapse confocal microscopy. Food Hydrocolloids, 98, Article 105228.

Somaratne, G., Nau, F., Ferrua, M. J., Singh, J., Ye, A., Dupont, D., ... Floury, J. (2020c).

Characterization of egg white gel microstructure and its relationship with pepsin diffusivity. Food Hydrocolloids, 98, Article 105258.

Somaratne, G., Reis, M. M., Ferrua, M. J., Ye, A., Nau, F., Floury, J., ... Singh, J. (2019). Mapping the spatiotemporal distribution of acid and moisture in food structures during gastric juice diffusion using hyperspectral imaging. Journal of Agricultural and Food Chemistry, 67(33), 9399-9410.

Sridharan, G., \& Shankar, A. A. (2012). Toluidine blue: A review of its chemistry and clinical utility. Journal of Oral and Maxillofacial Pathology, 16(2), 251.

Tian, J., Chen, S., Wu, C., Chen, J., Du, X., Chen, J., ... Ye, X. (2016). Effects of preparation methods on potato microstructure and digestibility: An in vitro study. Food Chemistry, 211, 564-569.

Tumuhimbise, G. A., Namutebi, A., \& Muyonga, J. H. (2009). Microstructure and in vitro beta carotene bioaccessibility of heat processed orange fleshed sweet potato. Plant Foods for Human Nutrition, 64(4), 312-318.

Van Loo-Bouwman, C. A., Naber, T. H. J., Minekus, M., Van-Breemen, R. B., Hulshof, P. J. M., \& Schaafsma, G. (2014). Food matrix effects on bioaccessibility of $\beta$-carotene can be measured in an in vitro gastrointestinal model. Journal of Agricultural and Food Chemistry, 62(4), 950-955. 